\title{
One-step nucleic acid amplification analysis of sentinel lymph nodes in papillary thyroid cancer patients
}

Krzysztof A. Kaczka, Lech Pomorski

Department of General and Oncological Surgery, Medical University of Lodz, Lodz, Poland

Submitted: 26 January 2016

Accepted: 2 October 2016

Arch Med Sci 2017; 13, 6: 1416-1426

DOI: https://doi.org/10.5114/aoms.2017.65466

Copyright @ 2017 Termedia \& Banach

\section{Abstract}

Introduction: It is essential to look for methods to define the need for central lymphadenectomy for papillary thyroid cancer patients. The aim is to determine the efficacy of one-step nucleic acid amplification (OSNA) and sentinel lymph node (SLN) biopsy in the intraoperative detection of nodal involvement.

Material and methods: This prospective, experimental study enrolled 49 patients with clinically negative lymph nodes. Intraoperatively, $1 \%$ Patent Blue dye was injected intratumorally. Lymph nodes that stained blue were defined as SLNs. They were directly cut into blocks at 2-mm intervals. Nonadjacent blocks were subjected to either the OSNA assay or histological examination.

Results: Sixty-five SLNs were found in 43 (87.8\%) patients. There were 20 (30.8\%) histopathologically positive SLNs. According to the OSNA, 22 (33.8\%) SLNs were positive. The OSNA results were different from histopathology in $8(12.3 \%)$ SLNs. The OSNA gave a positive result in $5(7.7 \%)$ SLNs, while they were not involved according to the histopathology. However, OSNA upstaged $\mathrm{N}$ status from NO to $\mathrm{N} 1$ only in $2(3.1 \%)$ patients. Inverse results (histopathology +, OSNA-) were obtained in $3(4.6 \%)$ SLNs. Positive and negative predictive values (PPV and NPV) for OSNA were 0.77 and 0.93 , respectively. The concordance rate between examinations was $85.5 \%$.

Conclusions: In some patients with clinically negative lymph nodes, OSNA and SLN biopsy may prevent unnecessary central lymphadenectomy. On the other hand, the sentinel lymph node biopsy may reveal the presence of potentially involved sentinel lymph nodes outside the central compartment. These SLNs can also be assessed by means of OSNA.

Key words: papillary thyroid cancer, one-step nucleic acid amplification, lymph nodes.

\section{Introduction}

The most suitable strategy for the treatment of patients with papillary thyroid cancer (PTC) is total thyroidectomy along with the dissection of all clinically apparent metastatic lymph nodes. There is considerable controversy concerning the approach to lymphadenectomy in PTC patients with clinically NO lymph nodes. The incidence of lymph node metastases is relatively high in PTC patients, even in the presence of small tumors, so the likelihood of local relapse can be reduced by routine central lymphadenectomy. However, routine central compartment lymph node dissection causes more recurrent laryngeal nerve damage and permanent

\author{
Corresponding author: \\ Krzysztof A. Kaczka MD \\ Department of General \\ and Oncological Surgery \\ Medical University of Lodz \\ 251 Pomorska St \\ 92-213 Lodz, Poland \\ Phone: +48 503068786 \\ E-mail: krzysztofkaczka@ \\ poczta.fm
}


hypoparathyroidism. Therefore, some surgeons perform selective lymphadenectomy of the central compartments only when there is evidence of lymph node involvement.

Nowadays, sentinel lymph node (SLN) biopsy is commonly applied in melanoma and breast cancer patients, but its use is investigated in other types of solid tumors, including PTC. According to the concept of SLN, that lymph node is the first node affected by metastasis, and if it can be shown to be negative it is highly unlikely that others lymph nodes are affected. Thus, SLN biopsy allows the number of complications associated with unnecessary lymph node dissection to be reduced. The SLN in PTC patients should be evaluated intraoperatively to avoid a potentially more difficult reoperation of the neck. There are several methods for the intraoperative evaluation of lymph nodes, such as frozen section, imprint biopsy and molecular techniques.

To the best of our knowledge, thyroid lymph nodes have only been examined by means of frozen section [1, 2]. Frozen section examination has two shortcomings: it gives false negative results for up to $23.3 \%$ of positive SLNs [1]; and it has limited specificity in detecting micrometastases [3]. Additionally, this examination cannot be performed in many hospitals because pathological examinations are outsourced to other hospitals or pathological centers. Therefore, there is a need to search for new, automated methods for the evaluation of lymph nodes. Probably, as in other cancer types, the addition of molecular techniques to standard histopathology should improve the accuracy of the intraoperative assessment of SLNs in thyroid carcinoma [4-8].

A number of molecular diagnostic assays based on the quantitative reverse transcription polymerase chain reaction have been developed for the intra-operative diagnosis of lymph node metastases. These methods can examine the whole lymph nodes and are expected to become an alternative to conventional histological examination. However, these tests are not used in routine practice, probably because they are complex and time-consuming. Therefore, hematoxylin and eosin staining continues to be the gold standard in lymph node evaluation. The one-step nucleic acid (OSNA) assay is a recently introduced molecular method, which is based on reverse transcription loop mediated isothermal amplification (RT-LAMP) of cytokeratin 19 (CK19) mRNA as its sole marker. That technique was invented by Notomi et al. [9]. In this system, the CK19 mRNA is directly and rapidly amplified from the supernatant of homogenized lymph nodes. Neither purifying mRNA nor changing temperatures during amplification are needed, unlike in PCR, so the results are available within $30 \mathrm{~min}$ and four lymph nodes can be si- multaneously analyzed. The OSNA procedure is automated and can be performed even in an operating theatre. The first application of OSNA was presented by Tsujimoto et al. for breast cancer. The compliance rate of the intraoperative histopathological examination and OSNA assay was $98.2 \%$ for all lymph nodes, including $96.4 \%$ for sentinel lymph nodes [10]. That technique has become a real alternative to the standard histopathological examination in Spain [11]. Its utility has been examined in other cancers. The OSNA appears to be a promising tool for the detection of lymph node micro- and macrometastases in sentinel lymph nodes in colorectal cancer patients [12]. It resulted in upstaging of $15.3 \%$ to $25.2 \%$ of colon cancer patients with negative lymph nodes after standard H\&E examination [12-14]. This technique showed the sensitivity of lymph node metastasis detection in gastric cancer patients as high as that of the histological examination of blocks sectioned at 2-mm intervals [15].

The OSNA is already being applied in many malignant neoplasms: lung cancer, head and neck squamous cancer, endometrial cancer and cervical cancer [15-21]. The OSNA technique was evaluated in two studies on thyroid cancer patients. Their results for the detection of sentinel lymph nodes were similar to those obtained using standard histopathology or molecular techniques [22, 23]. The aim of the study is to determine the efficacy of OSNA and SLN biopsy in the intraoperative detection of nodal involvement. To the best of our knowledge, it is the first publication concerning this matter in thyroid cancer.

\section{Material and methods}

\section{General information}

This research was designed as a prospective, experimental study. The Ethical Commission of the Medical University of Lodz approved the study protocol.

The study was done in compliance with the Declaration of Helsinki.

All patients were informed about the investigational purpose of the procedure and provided their written informed consent. This prospective study enrolled 49 patients who underwent total thyroidectomy and elective bilateral central lymph node dissection (level $\mathrm{VI}$ according to the WHO classification) with or without lateral lymph node dissection (levels II-V according to the WHO classification). The results of the OSNA assay did not affect the operative procedure.

The kind of the operation was in accordance with the guidelines of most surgical societies [24, 25].

All operations were performed by two experienced endocrine surgeons (more than 50 thyroid 
operations a year). The patients were suspected of or diagnosed with thyroid carcinoma based on fine needle aspiration biopsy (FNAB) before the operation. Only patients primarily operated on were included in the study.

On clinical examination, all patients had clinically negative lymph nodes. All patients also underwent thyroid and neck ultrasonography, and no patient had evidence of lymph node enlargement.

Exclusion criteria included: evidence of lymph node involvement, clinically evident local or distant metastases, macroscopically infiltrating tumors, benign thyroid disease, a history of previous neck surgery, radioiodine treatment before the operation, pregnancy or active breastfeeding, and significant comorbidities.

\section{Surgical technique}

The procedure was performed with the patients under general anesthesia as follows. after a standard transverse cervical incision had been made, cutaneous flaps were developed. The thyroid gland was exposed by the separation and lateralization of the strap muscles. Parathyroid glands were identified. Subsequently, $1 \%$ Patent Blue dye (Guerbet GmbH Germany) was injected intratumorally, very slowly, under low pressure, using a 27-G needle and insulin syringe. Care was taken not to accidentally stain the surrounding structures. $0.5 \mathrm{ml}$ was injected if the diameter was $2 \mathrm{~cm}$ or below. $1 \mathrm{ml}$ of blue dye was used for tumors larger than $2 \mathrm{~cm}$. Lymph nodes that stained blue were defined as SLNs. Data were recorded with respect to the lymph node size, number, and anatomical localization. Frozen section examination was not performed.

\section{Lymph nodes workup}

Lymph nodes $\geq 5 \mathrm{~mm}$ in the greatest dimension were included in the study for histopathology as well as OSNA. The cutoff size of $5 \mathrm{~mm}$ was chosen for technical reasons. If the lymph nodes are smaller than $5 \mathrm{~mm}$, then it is technically impossible to cut lymph nodes into 4 blocks and perform histopathological and molecular analysis. These lymph nodes were investigated only by histopathology. Lymph nodes were meticulously harvested from the fatty tissue and directly cut into blocks at 2-mm intervals with cutting devices developed by Tsujimoto et al. [10].

Nonadjacent blocks were subjected to either the OSNA assay or histological examination. Blocks for the OSNA were pooled and analyzed together. They were shock-frozen in liquid nitrogen and stored at $-70^{\circ} \mathrm{C}$ until molecular analysis was performed. The other blocks were cut and stained with hematoxylin and eosin, and analyzed by histological examination.

\section{Histopathology procedure}

The final histological examination consisted in a detailed analysis of the lymph node tissue sections embedded in paraffin blocks. All specimens were examined by experienced specialists in clinical pathology, using a conventional optical microscope. To ensure objectivity, the final histological results were based on the conclusions of two independent pathologists, blinded to OSNA results. Any evidence of metastatic cellularity was considered to be positive for lymphatic dissemination.

\section{OSNA procedure}

The OSNA examination for each lymph node included the homogenization of tissue in a mRNAstabilizing solution and subsequent amplification. It was performed automatically by the reverse transcription loop-mediated isothermal amplification (RT-LAMP) of CK19 mRNA in the RD-100i detection engine (Sysmex) without prior mRNA isolation and purification as recommended for OSNA elsewhere. The RD-100i system includes a ready-to-use reagent kit (Lynoamp, Sysmex) consisting of the enzyme, primers, nucleotides, buffer necessary for CK19 mRNA amplification and components for assay validation (calibrators, positive and negative controls). The technique uses six primers, which increase the specificity and speed of the reaction. The expression level of CK19 mRNA is detected by the real-time monitoring of turbidity changes caused by an increase in the concentration of magnesium pyrophosphate, a by-product of the amplification reaction. It is possible to analyze up to 4 SLNs at the same time. The SLN was assessed as OSNA (+) when the CK 19 mRNA copy number was more than $2.5 \times 10^{2}$ copies/ $\mu$ l.

\section{Results}

The SLNs were found in 43 (87.8\%) of 49 primarily included patients.

A further analysis was carried out only in the group of patients with detected SLNs. The mean age of the investigated group was 50.1 years. There were 10 men and 33 women (F/M ratio was 4.3/1). Thirty-eight (88.4\%) patients were diagnosed with the classical variant of papillary thyroid cancer (CVPC) and 5 (11.6\%) with the follicular variant of papillary thyroid cancer (Tables I and II).

\section{Distribution of sentinel lymph nodes}

There were found 65 SLNs. The number of SLNs ranged from 1 to 4 (mean 1.5 per patient). In 
terms of SLN distribution in the neck, 55 (84.6\%) of all the SLNs were located in the central compartment area (Figure 1).

Twenty-one $(32.3 \%)$ of them were situated in the right central compartment on the same side of the tumor. Thirty (46.2\%) SLNs were found in the left central compartment on the same side of the tumor. There were 4 (6.2\%) SLNs on the opposite side with respect to the tumor: $3(4.6 \%)$ in the left central compartment and 1 (1.5\%) in the right compartment (Figure 1).

Ten SLNs were found only outside the central compartment. Three patients had 2, 3 and 1 SLNs respectively in the right lateral compartment. One patient had 2 SLNs in the upper mediastinum. Two patients had 1 SLN in two compartments: the central and left lateral.

\section{Histopathology and OSNA results of SLNS}

There were 20 (30.8\%) histopathologically positive SLNs. According to the OSNA assay, 22 (33.8\%) SLNs were positive. The OSNA results were different from histopathology in 8 (12.3\%) SLNs (Figure 1). The OSNA assay gave a positive result in $5(7.7 \%)$ SLNs, while they were not involved according to histopathology.

The OSNA upstaged N status from NO to N1 only in 2 patients (Figure 2, Table III). Inverse results (histopathology +, OSNA-) were obtained in $3(4.6 \%)$ SLNs. OSNA downstaged $\mathrm{N}$ status from $\mathrm{N} 1$ to NO in only 1 patient (Figure 2, Table III). In our series PPV and NPV for OSNA were 0.77 and 0.93 , respectively. The concordance rate between examinations was $85.5 \%$.

\section{Discussion}

The biopsy of the SLN is not a standard procedure in thyroid cancer. In 1998, Kelemen et al. first described the use of the dye method in mapping the SLN in thyroid cancer. The sentinel lymph node was found in 15 out of 17 patients enrolled in the study, including all the 12 patients postoperatively diagnosed with thyroid cancer.

Five of those had metastases in lymph nodes [26]. In 1999, Gallowitsch et al. and subsequently, in 2001, Sahin et al. applied the radioisotope method to localize the SLN in thyroid cancer patients $[27,28]$. However, until now, in a majority of cases of sentinel lymph node mapping in thyroid carcinoma, the dye method has solely been employed [29, 30]. Similarly to breast cancer or melanoma, routine SLN biopsies could bring several potential benefits. Those benefits, however, are the greatest when the detected SLNs are assessed using a reliable intraoperative method. The best would be a quantitative, automated method applying an easily operated device. Perhaps such
Table I. TNM staging of included patients

\begin{tabular}{|lc|}
\hline TNM staging & No. of patients (\%) \\
\hline$T_{1 a} N_{0} M_{0}$ & $6(13.9)$ \\
\hline$T_{1 a m} N_{0} M_{0}$ & $11(2.3)$ \\
\hline$T_{1 b} N_{0} M_{0}$ & $10(23.3)$ \\
\hline$T_{2} N_{0} M_{0}$ & $3(7.0)$ \\
\hline$T_{1 a} N_{1 a} M_{0}$ & $2(4.7)$ \\
\hline$T_{1 b} N_{1 b} M_{0}$ & $5(11.6)$ \\
\hline$T_{2} N_{1 a} M_{0}$ & $2(4.7)$ \\
\hline$T_{2} N_{1 b} M_{0}$ & $1(2.3)$ \\
\hline$T_{3} N_{1 a} M_{0}$ & $2(4.7)$ \\
\hline$T_{3} N_{1 b} M_{0}$ & \\
\hline
\end{tabular}

a method will be the OSNA assay. Therefore, the aim of this study was to evaluate the usefulness of the sentinel lymph node biopsy and OSNA method in determining the extent of lymph node removal in thyroid cancer patients. In our study, 65 SLNs were detected in 43 patients. The percentage of patients with detected SLNs did not differ from results obtained by other researchers. Except for the study by Peparini et al., conducted on a very small group of patients, the percentage has always exceeded $60 \%$ [31]. It was above $90 \%$ in many studies [30-32]. In a meta-analysis done by the authors of this study, it was found that the detection rate of the sentinel lymph node using patent blue was 68.3\% [32]. Perhaps applying another method, along with the dye method, in localizing the SLN would result in an increased percentage of patients in whom the SLN would be found. However, in thyroid cancer, less commonly than in other cancers, the radioisotope method is used to detect the SLN.

The introduction of the sentinel lymph node biopsy, as a standard procedure, in thyroid cancer could bring several potential benefits. However, only the simultaneous application of the sentinel lymph node biopsy and intraoperative lymph node assessment method would contribute to the enhancement of their benefits. At present, OSNA is the most popular intraoperative molecular lymph node assessment method. Potential benefits may accrue from the simultaneous application of both the methods.

It may reduce the number of unnecessary lymphadenectomies and thus postoperative hypoparathyroidism and recurrent laryngeal nerve paralysis cases. In our study, histopathology showed metastases in 20 (30.8\%) SLNs in 11 (2.56\%) patients. There were 22 (33.8\%) OSNA-positive SLNs. The concordance rate between histopathology and OSNA was $85.5 \%$. The OSNA results were different from histopathology in only 8 (12.3\%) SLNs. 
Krzysztof A. Kaczka, Lech Pomorski

Table II. Original data for study subjects

\begin{tabular}{|c|c|c|c|c|c|c|}
\hline No. & Age [years] & Sex & Clinical stage & Histologic type & Site & $\begin{array}{c}\text { Tumor size } \\
\text { [mm] }\end{array}$ \\
\hline 1 & 41 & $\mathrm{~F}$ & $\mathrm{~T}_{2} \mathrm{~N}_{1 \mathrm{a}} \mathrm{M}_{0}$ & CVPC & $\mathrm{RL}$ & 30 \\
\hline 2 & 43 & M & $\mathrm{T}_{1 \mathrm{~b}} \mathrm{~N}_{0} \mathrm{M}_{0}$ & CVPC & $\mathrm{LL}$ & 20 \\
\hline 3 & 50 & $\mathrm{~F}$ & $\mathrm{~T}_{1 \mathrm{a}} \mathrm{N}_{0} \mathrm{M}_{0}$ & CVPC & $R L$ & 7 \\
\hline 4 & 49 & $\mathrm{~F}$ & $\mathrm{~T}_{1 \mathrm{a}} \mathrm{N}_{0} \mathrm{M}_{0}$ & CVPC & $\mathrm{RL}$ & 9 \\
\hline 5 & 65 & $\mathrm{~F}$ & $\mathrm{~T}_{1 \mathrm{am}} \mathrm{N}_{0} \mathrm{M}_{0}$ & CVPC & $\mathrm{RR}$ & 2 and 7 \\
\hline 6 & 68 & $M$ & $\mathrm{~T}_{1 \mathrm{~b}} \mathrm{~N}_{1 \mathrm{~b}} \mathrm{M}_{0}$ & CVPC & $\mathrm{LL}$ & 20 \\
\hline 7 & 47 & $\mathrm{~F}$ & $\mathrm{~T}_{1 \mathrm{~b}} \mathrm{~N}_{0} \mathrm{M}_{0}$ & CVPC & $\mathrm{RL}$ & 18 \\
\hline 8 & 37 & $\mathrm{~F}$ & $\mathrm{~T}_{2} \mathrm{~N}_{1 \mathrm{~b}} \mathrm{M}_{0}$ & CVPC & $\mathrm{LL}$ & 25 \\
\hline 9 & 73 & $\mathrm{~F}$ & $\mathrm{~T}_{1 \mathrm{~b}} \mathrm{~N}_{0} \mathrm{M}_{0}$ & CVPC & $\mathrm{LL}$ & 20 \\
\hline 10 & 47 & $M$ & $\mathrm{~T}_{2} \mathrm{~N}_{1 \mathrm{a}} \mathrm{M}_{0}$ & CVPC & $\mathrm{LL}$ & 30 \\
\hline 11 & 34 & $\mathrm{~F}$ & $\mathrm{~T}_{1 \mathrm{a}} \mathrm{N}_{1 \mathrm{a}} \mathrm{M}_{0}$ & FVPC & $\mathrm{RL}$ & 20 \\
\hline 12 & 65 & $\mathrm{~F}$ & $\mathrm{~T}_{3} \mathrm{~N}_{1 \mathrm{~b}} \mathrm{M}_{0}$ & CVPC & $\mathrm{LL}$ & 9 \\
\hline 13 & 71 & M & $\mathrm{T}_{2} \mathrm{~N}_{0} \mathrm{M}_{0}$ & CVPC & $\mathrm{RL}$ & 25 \\
\hline 14 & 43 & $\mathrm{~F}$ & $\mathrm{~T}_{1 \mathrm{~b}} \mathrm{~N}_{0} \mathrm{M}_{0}$ & CVPC & $\mathrm{RL}$ & 20 \\
\hline 15 & 53 & $\mathrm{~F}$ & $\mathrm{~T}_{1 \mathrm{a}} \mathrm{N}_{1 \mathrm{a}} \mathrm{M}_{0}$ & CVPC & $\mathrm{LL}$ & 15 \\
\hline 16 & 54 & $\mathrm{~F}$ & $\mathrm{~T}_{2} \mathrm{~N}_{0} \mathrm{M}_{0}$ & CVPC & $\mathrm{RL}$ & 23 \\
\hline 17 & 45 & $\mathrm{~F}$ & $\mathrm{~T}_{1 \mathrm{~b}} \mathrm{~N}_{0} \mathrm{M}_{0}$ & CVPC & $\mathrm{RL}$ & 12 \\
\hline 18 & 56 & $\mathrm{~F}$ & $\mathrm{~T}_{1 \mathrm{a}} \mathrm{N}_{0} \mathrm{M}_{0}$ & CVPC & $\mathrm{RL}$ & 8 \\
\hline 19 & 43 & $\mathrm{~F}$ & $\mathrm{~T}_{2} \mathrm{~N}_{1 \mathrm{a}} \mathrm{M}_{0}$ & CVPC & $\mathrm{LL}$ & 28 \\
\hline 20 & 19 & $M$ & $\mathrm{~T}_{3} \mathrm{~N}_{1 \mathrm{~b}} \mathrm{M}_{0}$ & CVPC & $\mathrm{LL}$ & 12 \\
\hline 21 & 49 & $\mathrm{~F}$ & $\mathrm{~T}_{2} \mathrm{~N}_{1 \mathrm{a}} \mathrm{M}_{0}$ & CVPC & $\mathrm{LL}$ & 26 \\
\hline 22 & 54 & $\mathrm{~F}$ & $\mathrm{~T}_{1 \mathrm{a}} \mathrm{N}_{1 \mathrm{a}} \mathrm{M}_{0}$ & CVPC & $R L$ & 16 \\
\hline 23 & 34 & $\mathrm{~F}$ & $\mathrm{~T}_{1 \mathrm{a}} \mathrm{N}_{0} \mathrm{M}_{0}$ & CVPC & $\mathrm{LL}$ & 6 \\
\hline 24 & 46 & $\mathrm{~F}$ & $\mathrm{~T}_{2} \mathrm{~N}_{0} \mathrm{M}_{0}$ & CVPC & $\mathrm{RL}$ & 24 \\
\hline 25 & 71 & $\mathrm{~F}$ & $\mathrm{~T}_{2} \mathrm{~N}_{1 \mathrm{a}} \mathrm{M}_{0}$ & FVPC & $\mathrm{RL}$ & 31 \\
\hline 26 & 29 & $\mathrm{~F}$ & $\mathrm{~T}_{1 \mathrm{~b}} \mathrm{~N}_{0} \mathrm{M}_{0}$ & CVPC & $\mathrm{LL}$ & 11 \\
\hline 27 & 68 & $\mathrm{~F}$ & $\mathrm{~T}_{2} \mathrm{~N}_{1 \mathrm{~b}} \mathrm{M}_{0}$ & CVPC & $\mathrm{RL}$ & 24 \\
\hline 28 & 67 & $\mathrm{~F}$ & $\mathrm{~T}_{2} \mathrm{~N}_{0} \mathrm{M}_{0}$ & FVPC & $\mathrm{LL}$ & 27 \\
\hline 29 & 56 & $\mathrm{~F}$ & $\mathrm{~T}_{1 \mathrm{~b}} \mathrm{~N}_{0} \mathrm{M}_{0}$ & CVPC & $\mathrm{RL}$ & 14 \\
\hline 30 & 48 & $\mathrm{~F}$ & $\mathrm{~T}_{3} \mathrm{~N}_{1 \mathrm{a}} \mathrm{M}_{0}$ & CVPC & $\mathrm{LL}$ & 7 \\
\hline 31 & 23 & M & $\mathrm{T}_{1 \mathrm{~b}} \mathrm{~N}_{1 \mathrm{~b}} \mathrm{M}_{0}$ & CVPC & LL & 15 \\
\hline 32 & 28 & $\mathrm{~F}$ & $\mathrm{~T}_{1 \mathrm{~b}} \mathrm{~N}_{0} \mathrm{M}_{0}$ & CVPC & $\mathrm{RL}$ & 19 \\
\hline 33 & 56 & $\mathrm{~F}$ & $\mathrm{~T}_{1 \mathrm{~b}} \mathrm{~N}_{1 \mathrm{a}} \mathrm{M}_{0}$ & CVPC & I/RL & 14 \\
\hline 34 & 71 & $M$ & $\mathrm{~T}_{2} \mathrm{~N}_{0} \mathrm{M}_{0}$ & CVPC & RL1 & 28 \\
\hline 35 & 63 & $\mathrm{~F}$ & $\mathrm{~T}_{2} \mathrm{~N}_{0} \mathrm{M}_{0}$ & CVPC & $\mathrm{LL}$ & 21 \\
\hline 36 & 40 & $\mathrm{~F}$ & $\mathrm{~T}_{1 \mathrm{~b}} \mathrm{~N}_{0} \mathrm{M}_{0}$ & CVPC & $\mathrm{RL}$ & 16 \\
\hline 37 & 28 & $\mathrm{~F}$ & $\mathrm{~T}_{2} \mathrm{~N}_{0} \mathrm{M}_{0}$ & FVPC & $\mathrm{LL}$ & 24 \\
\hline 38 & 43 & $\mathrm{~F}$ & $\mathrm{~T}_{2} \mathrm{~N}_{0} \mathrm{M}_{0}$ & CVPC & $\mathrm{LL}$ & 29 \\
\hline 39 & 59 & $M$ & $\mathrm{~T}_{2} \mathrm{~N}_{0} \mathrm{M}_{0}$ & CVPC & $\mathrm{RL}$ & 34 \\
\hline 40 & 74 & $M$ & $\mathrm{~T}_{1 \mathrm{~b}} \mathrm{~N}_{0} \mathrm{M}_{0}$ & FVPC & $\mathrm{RL}$ & 18 \\
\hline 41 & 54 & $\mathrm{~F}$ & $\mathrm{~T}_{1 \mathrm{a}} \mathrm{N}_{0} \mathrm{M}_{0}$ & CVPC & $R L$ & 6 \\
\hline 42 & 38 & M & $\mathrm{T}_{2} \mathrm{~N}_{0} \mathrm{M}_{0}$ & CVPC & $\mathrm{RL}$ & 31 \\
\hline 43 & 52 & $\mathrm{~F}$ & $\mathrm{~T}_{1 \mathrm{a}} \mathrm{N}_{0} \mathrm{M}_{0}$ & CVPC & $\mathrm{LL}$ & 8 \\
\hline
\end{tabular}

$F$-female, $M$ - male, CVPC - classical variant of papillary thyroid cancer, FVPC - follicular variant of papillary thyroid cancer, $R L$ - right lobe, $L L-$ left lobe. 


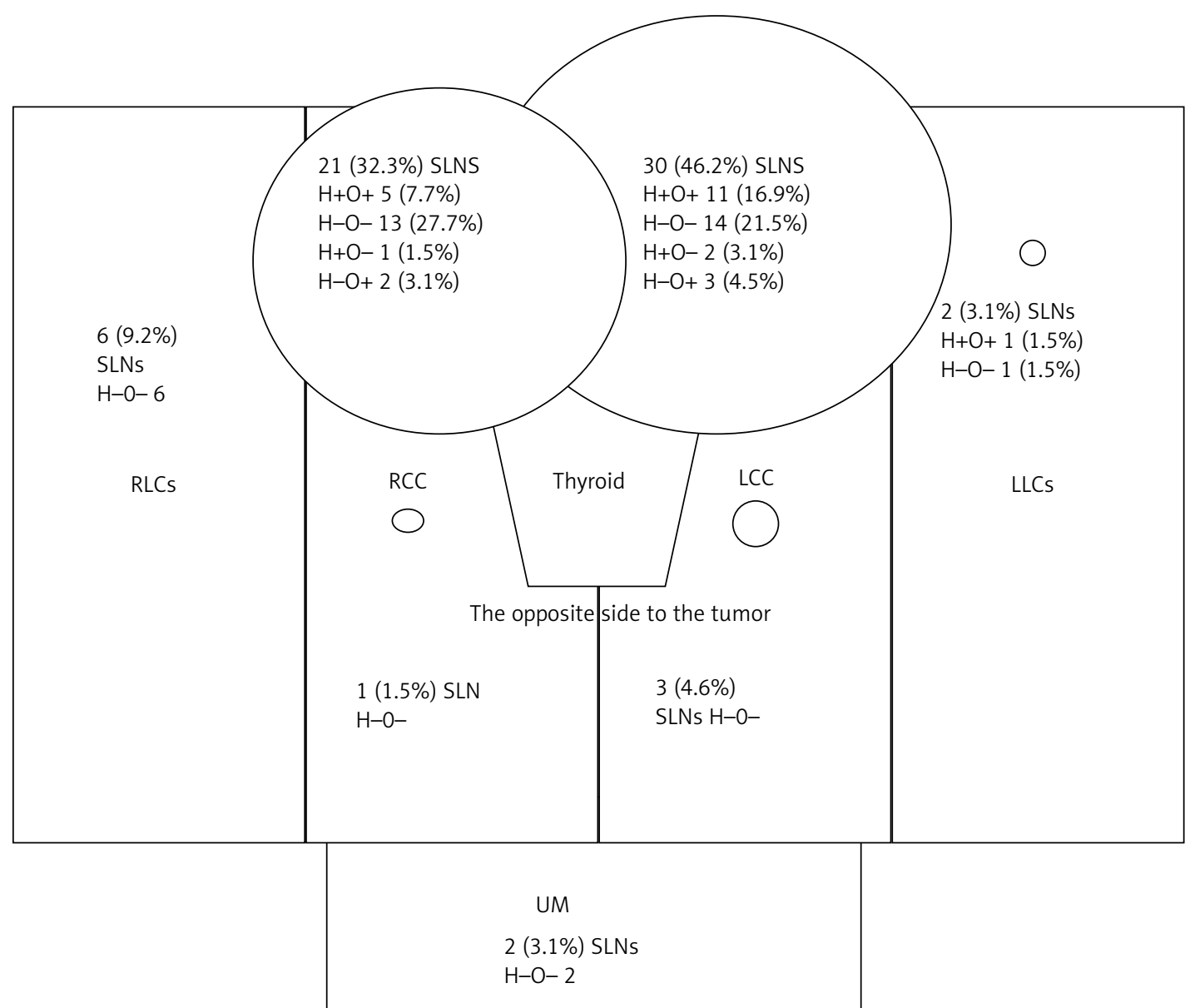

Figure 1. Distribution of SLNs and histopathology and OSNA results

$\mathrm{H+}-$ positive result of histopathology examination, $\mathrm{H}--$ negative results of histopathology examination, $\mathrm{O}_{+}-$positive result of OSNA examination, $O_{-}-$negative results of OSNA examination, RCC - right central compartment (level VI according to the WHO classification), LCC - left central compartment (level VI according to the WHO classification), RLCS - right lateral compartments (levels II-V according to the WHO classification), LLCS - left lateral compartments (levels II-V according to the WHO classification), UM - upper mediastinum.

Three of them were OSNA-positive and histopathologically negative, but the OSNA examination determined TNM staging ( $\mathrm{N}$ status) lower than histopathology in only 1 person (patient 31 - Table III). The OSNA assay gave positive results in $5(7.7 \%)$ SLNs, while they were not affected according to histopathology. However, only in 2 cases (patient 23 and 38) did OSNA upstage the $\mathrm{N}$ status from N0 to N1.

As there was no reliable intraoperative examination, we performed central lymphadenectomy in all patients. If we consider histopathology the gold standard, it was done unnecessarily in 29 (67.4\%) of 43 patients with clinically negative lymph nodes which were negative in histopathology.

If we had relied on the SLNB and OSNA combination, 28 (65.1\%) patients would not have had any lymphadenectomy done. Among this group of patients, only in 1 (3.6\%) would lymph node metastases have been left.

In some thyroid cancer patients there may occur the phenomenon of skip metastases, i.e., the presence of thyroid cancer metastases in lateral nodes with metastasis-free lymph nodes of the central compartment. They can be observed in approximately one-fifth of patients [33-35]. The presence of skip metastases may result from the presence of alternative lymph drainage routes from the primary focus or disturbed outflow from the primary focus due to postinflammatory, postirradiation or posttraumatic, including postoperative, lesions [36]. The above suggests that elective lymphadenectomy should preferably be performed in the lateral compartment of the neck. Perhaps the introduction of the sentinel lymph node biopsy would enable identification of a group of patients in whom the nodes of the lateral compartment of the neck ought to be removed. Paradoxically, in such cases, the SLNB expands the scope of the lymphadenectomy. The usefulness of applying the SLNB for such a purpose has been proved. Chow et al. found sentinel lymph nodes solely in the lateral compartment in $10 \%$ of patients. In others, sentinel lymph nodes were located in both the lat- 


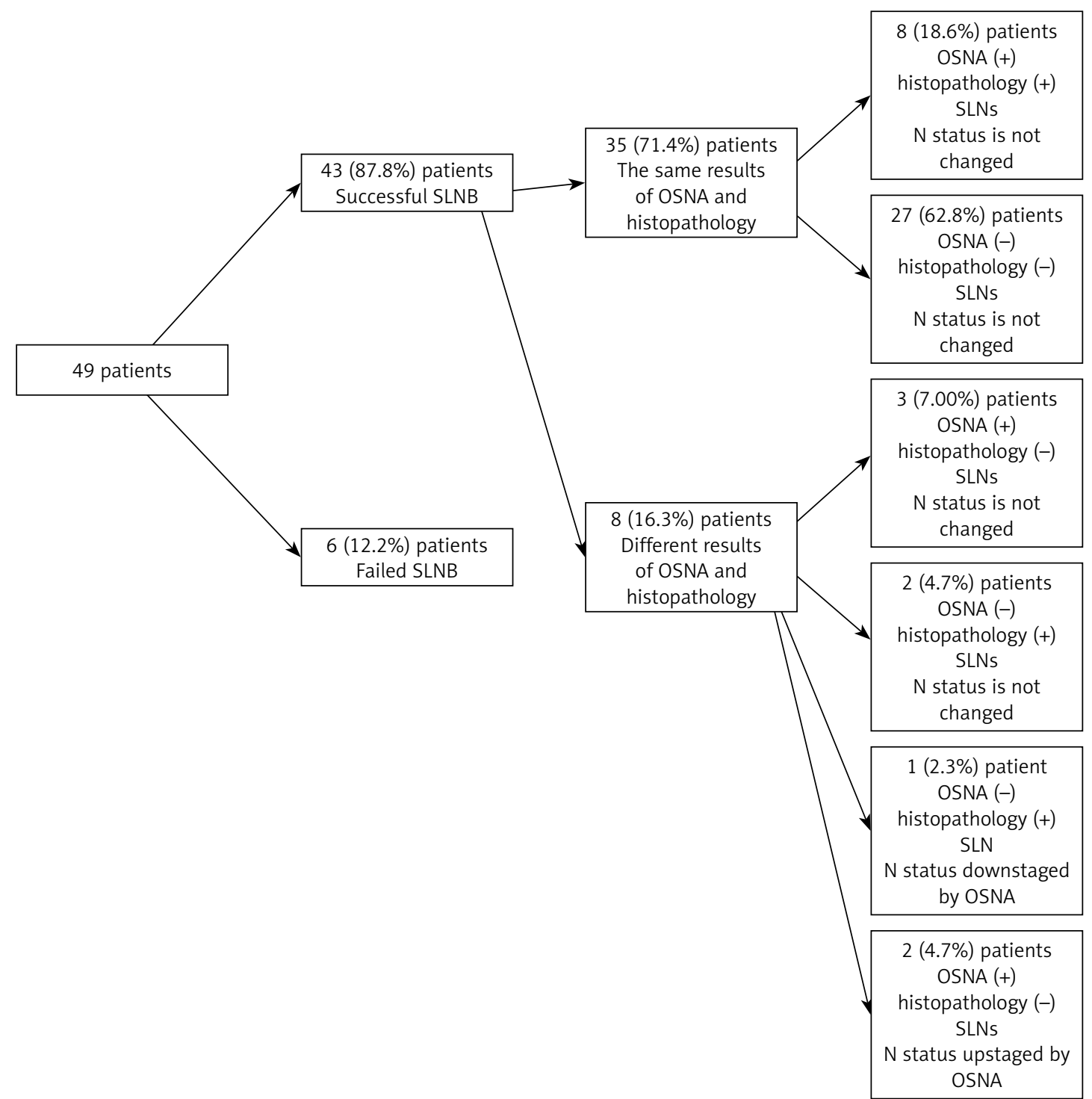

Figure 2. Potential impact of SLNB and OSNA results on TNM status

eral and central compartments [37]. In our study, the presence of sentinel lymph nodes in the lateral compartments of the neck was detected in 3 (7.0\%) patients. In 2 of those, no neoplastic cells were found in histopathology and the OSNA results were not positive.

In 1 patient, two sentinel lymph nodes were detected in the central compartment and one in the lateral compartment. Histopathology indicated metastases in all those nodes. Positive OSNA results were obtained for one node from the central and one from the lateral compartment. Based on the OSNA, despite the detection of sentinel lymph nodes outside the central compartment in 2 of 3 patients, only one would have undergone lateral lymphadenectomy.

The SLNB and intraoperative examination may help to determine the appropriate treatment of follicular tumors. Such an application of the sentinel lymph node biopsy was presented by Takeya- ma et al. [38]. In patients with preoperatively diagnosed follicular tumor, the sentinel lymph node biopsy and intraoperative frozen sample examination enable one to determine the scope of the primary procedure. The negative result of the intraoperative examination allows one to avoid performing central lymphadenectomy regardless of whether the patient will ultimately be diagnosed with follicular cancer or follicular tumor. The positive result of the intraoperative sentinel lymph node material examination is tantamount to the diagnosis of cancer and makes lymphadenectomy necessary. In many hospitals where it is not possible to perform frozen section, OSNA could be an alternative to that intraoperative examination. We did not include patients with follicular tumors. However, we obtained a high percentage of detected SLN (87.8\%) and a low percentage of false negative OSNA results - only for 1 (2.3\%) patient. Perhaps the combination of SLNB and OSNA may 
Table III. Localization of SLNs and their histopathology and OSNA results

\begin{tabular}{|c|c|c|c|c|c|c|}
\hline \multirow[t]{2}{*}{ Patient } & \multirow[t]{2}{*}{ Examination } & \multicolumn{5}{|c|}{ Number of metastatic/total SLNs } \\
\hline & & $\mathrm{RCC}$ & LCC & RLCs & LLCs & UM \\
\hline 1 & $\begin{array}{l}\text { Histopathology } \\
\text { OSNA }\end{array}$ & $\begin{array}{l}2 / 2 \\
2 / 2\end{array}$ & & & & \\
\hline 2 & $\begin{array}{l}\text { Histopathology } \\
\text { OSNA }\end{array}$ & & $\begin{array}{l}0 / 1 \\
0 / 1\end{array}$ & & & \\
\hline 3 & $\begin{array}{l}\text { Histopathology } \\
\text { OSNA }\end{array}$ & & $\begin{array}{l}0 / 1 \\
0 / 1\end{array}$ & & & \\
\hline 4 & $\begin{array}{l}\text { Histopathology } \\
\text { OSNA }\end{array}$ & & & $\begin{array}{l}0 / 2 \\
0 / 2\end{array}$ & & \\
\hline 5 & $\begin{array}{l}\text { Histopathology } \\
\text { OSNA }\end{array}$ & $\begin{array}{l}0 / 1 \\
0 / 1\end{array}$ & & & & \\
\hline 6 & $\begin{array}{l}\text { Histopathology } \\
\text { OSNA }\end{array}$ & & $\begin{array}{l}1 / 1 \\
1 / 1\end{array}$ & & & \\
\hline 7 & $\begin{array}{l}\text { Histopathology } \\
\text { OSNA }\end{array}$ & $\begin{array}{l}0 / 2 \\
0 / 2\end{array}$ & & & & \\
\hline 8 & $\begin{array}{l}\text { Histopathology } \\
\text { OSNA }\end{array}$ & & $\begin{array}{l}1 / 2 \\
2 / 2\end{array}$ & & $\begin{array}{l}1 / 1 \\
1 / 1\end{array}$ & \\
\hline 9 & $\begin{array}{l}\text { Histopathology } \\
\text { OSNA }\end{array}$ & & $\begin{array}{l}0 / 1 \\
0 / 1\end{array}$ & & $\begin{array}{l}0 / 1 \\
0 / 1\end{array}$ & \\
\hline 10 & $\begin{array}{l}\text { Histopathology } \\
\text { OSNA }\end{array}$ & & $\begin{array}{l}1 / 2 \\
2 / 2\end{array}$ & & & \\
\hline 11 & $\begin{array}{l}\text { Histopathology } \\
\text { OSNA }\end{array}$ & $\begin{array}{l}1 / 1 \\
1 / 1\end{array}$ & & & & \\
\hline 12 & $\begin{array}{l}\text { Histopathology } \\
\text { OSNA }\end{array}$ & & $\begin{array}{l}0 / 1 \\
0 / 1\end{array}$ & & & \\
\hline 13 & $\begin{array}{l}\text { Histopathology } \\
\text { OSNA }\end{array}$ & $\begin{array}{l}0 / 2 \\
0 / 2\end{array}$ & & & & \\
\hline 14 & $\begin{array}{l}\text { Histopathology } \\
\text { OSNA }\end{array}$ & $\begin{array}{l}0 / 1 \\
0 / 1\end{array}$ & & & & \\
\hline 15 & $\begin{array}{l}\text { Histopathology } \\
\text { OSNA }\end{array}$ & & $\begin{array}{l}2 / 3 \\
1 / 3\end{array}$ & & & \\
\hline 16 & $\begin{array}{l}\text { Histopathology } \\
\text { OSNA }\end{array}$ & & & $\begin{array}{l}0 / 3 \\
0 / 3\end{array}$ & & \\
\hline 17 & $\begin{array}{l}\text { Histopathology } \\
\text { OSNA }\end{array}$ & $\begin{array}{l}0 / 1 \\
0 / 1\end{array}$ & & & & \\
\hline 18 & $\begin{array}{l}\text { Histopathology } \\
\text { OSNA }\end{array}$ & $\begin{array}{l}0 / 1 \\
0 / 1\end{array}$ & & & & \\
\hline 19 & $\begin{array}{l}\text { Histopathology } \\
\text { OSNA }\end{array}$ & & $\begin{array}{l}2 / 2 \\
2 / 2\end{array}$ & & & \\
\hline 20 & $\begin{array}{l}\text { Histopathology } \\
\text { OSNA }\end{array}$ & & $\begin{array}{l}1 / 2 \\
1 / 2\end{array}$ & & & \\
\hline 21 & $\begin{array}{l}\text { Histopathology } \\
\text { OSNA }\end{array}$ & & $\begin{array}{l}0 / 1 \\
0 / 1\end{array}$ & & & \\
\hline 22 & $\begin{array}{l}\text { Histopathology } \\
\text { OSNA }\end{array}$ & & $\begin{array}{l}2 / 2 \\
2 / 2\end{array}$ & & & \\
\hline 23 & $\begin{array}{l}\text { Histopathology } \\
\text { OSNA1 }\end{array}$ & $\begin{array}{l}0 / 1 \\
1 / 1\end{array}$ & $\begin{array}{l}0 / 3 \\
0 / 3\end{array}$ & & & \\
\hline 24 & $\begin{array}{l}\text { Histopathology } \\
\text { OSNA }\end{array}$ & & $\begin{array}{l}0 / 1 \\
0 / 1\end{array}$ & & & \\
\hline 25 & $\begin{array}{l}\text { Histopathology } \\
\text { OSNA }\end{array}$ & & $\begin{array}{l}0 / 1 \\
0 / 1\end{array}$ & & & \\
\hline 26 & $\begin{array}{l}\text { Histopathology } \\
\text { OSNA }\end{array}$ & $\begin{array}{l}2 / 2 \\
1 / 2\end{array}$ & & & & \\
\hline
\end{tabular}


Table III. Cont.

\begin{tabular}{|c|c|c|c|c|c|c|}
\hline \multirow[t]{2}{*}{ Patient } & \multirow[t]{2}{*}{ Examination } & \multicolumn{5}{|c|}{ Number of metastatic/total SLNs } \\
\hline & & $\mathrm{RCC}$ & LCC & RLCs & LLCs & UM \\
\hline \multirow[t]{2}{*}{27} & Histopathology & $0 / 1$ & $0 / 1$ & & & \\
\hline & OSNA & $0 / 1$ & $0 / 1$ & & & \\
\hline \multirow[t]{2}{*}{28} & Histopathology & $1 / 1$ & & & & \\
\hline & OSNA & $1 / 1$ & & & & \\
\hline \multirow[t]{2}{*}{29} & Histopathology & & $0 / 1$ & & & \\
\hline & OSNA & & $0 / 1$ & & & \\
\hline \multirow[t]{2}{*}{30} & Histopathology & $0 / 1$ & & & & \\
\hline & OSNA & $0 / 1$ & & & & \\
\hline \multirow[t]{2}{*}{31} & Histopathology & & $1 / 2$ & & & \\
\hline & OSNA & & $0 / 2$ & & & \\
\hline \multirow[t]{2}{*}{32} & Histopathology & & $1 / 2$ & & & \\
\hline & OSNA & & $1 / 2$ & & & \\
\hline \multirow[t]{2}{*}{33} & Histopathology & & $1 / 2$ & & & \\
\hline & OSNA & & $2 / 2$ & & & \\
\hline \multirow[t]{2}{*}{34} & Histopathology & $0 / 1$ & & & & \\
\hline & OSNA & $0 / 1$ & & & & \\
\hline \multirow[t]{2}{*}{35} & Histopathology & & & & & $0 / 2$ \\
\hline & OSNA & & & & & $0 / 2$ \\
\hline \multirow[t]{2}{*}{36} & Histopathology & $0 / 1$ & & & & \\
\hline & OSNA & $0 / 1$ & & & & \\
\hline \multirow[t]{2}{*}{37} & Histopathology & & $0 / 1$ & & & \\
\hline & OSNA & & $0 / 1$ & & & \\
\hline \multirow[t]{2}{*}{38} & Histopathology & $0 / 1$ & & & & \\
\hline & OSNA & $1 / 1$ & & & & \\
\hline \multirow[t]{2}{*}{39} & Histopathology & $0 / 1$ & & & & \\
\hline & OSNA & $0 / 1$ & & & & \\
\hline \multirow[t]{2}{*}{40} & Histopathology & & $0 / 2$ & & & \\
\hline & OSNA & & $0 / 2$ & & & \\
\hline \multirow[t]{2}{*}{41} & Histopathology & & & $0 / 1$ & & \\
\hline & OSNA & & & $0 / 1$ & & \\
\hline \multirow[t]{2}{*}{42} & Histopathology OSNA13 & $0 / 1$ & & & & \\
\hline & & $0 / 1$ & & & & \\
\hline \multirow[t]{2}{*}{43} & Histopathology OSNA & & $0 / 1$ & & & \\
\hline & & & $0 / 1$ & & & \\
\hline
\end{tabular}

RCC - right central compartment, $L C C$ - left central compartment, RLCS - right lateral compartments, $L L C S$ - left lateral compartments, UM - upper mediastinum.

be used to determine the extent of surgery for follicular neoplasms.

It is laborious and expensive to perform molecular tests on material collected from all lymph nodes. The sentinel lymph node biopsy allows one to focus on one or two lymph nodes representative of all others. In large bowel cancer patients, such a procedure enabled a higher stage of the disease to be diagnosed [39].

In thyroid cancer, relapse occurs in a large number of patients despite the negative histopathology of lymph nodes. Perhaps the application of sentinel lymph node biopsy and OSNA may allow identification of a group of patients at a higher risk of relapse (histopathologically negative, OSNA positive). Perhaps those patients should be administered radio- active iodine. There were two such patients among our patients. They are in follow-up and have had no recurrence. Further studies should find a larger group of such patients to draw any conclusion.

In conclusion, it can be stated that it is relatively technically easy to perform the SLNB and OSNA. In some of the patients with clinically negative lymph nodes, the employment of those procedures may prevent unnecessary central lymphadenectomy and associated increased risk of recurrent laryngeal nerve and parathyroid gland damage. On the other hand, the sentinel lymph node biopsy may reveal the presence of potentially involved sentinel lymph nodes outside the central compartment. Similarly to the central compartment lymph nodes, those nodes can be assessed by means of 
OSNA. The application of OSNA in such a case may allow the extent of lymphadenectomy to be determined.

\section{Conflict of interest}

The authors declare no conflict of interest.

\section{References}

1. Jozaghi $\mathrm{Y}$, Richardson K, Anand S, et al. Frozen section analysis and sentinel lymph node biopsy in well differentiated thyroid cancer. J Otolaryngol Head Neck Surg 2013; 11: 48.

2. Raffaelli M, De Crea C, Sessa L, Fadda G, Bellantone C, Lombardi CP. Ipsilateral central neck dissection plus frozen section examination versus prophylactic bilateral central neck dissection in cNO papillary thyroid carcinoma. Ann Surg Oncol 2015; 22: 2302-8.

3. Garcia-Burillo A, Roca Bielsa I, Gonzalez O, et al. SPECT/ CT sentinel lymph node identification in papillary thyroid cancer: lymphatic staging and surgical management improvement. Eur J Nucl Med Mol Imaging 2013; 40: 1645-55.

4. Huynh KT, Bilchik AJ. Sentinel lymph node biopsy and nodal ultrastaging in colorectal cancer. Cancer J 2015; 21: 11-6.

5. Hoon DS, Bernet L, Cano R, Viale G. Molecular analysis of sentinel lymph nodes and search for molecular signatures of the metastatic potential of breast cancer. Q J Nucl Med Mol Imaging 2014; 58: 180-92.

6. Ferris RL, Stefanika P, Xi L, Gooding W, Seethala RR, Godfrey TE. Rapid molecular detection of metastatic head and neck squamous cell carcinoma as an intraoperative adjunct to sentinel lymph node biopsy. Laryngoscope 2012; 122: 1020-30.

7. Kupisz K, Stepulak A, Zdunek M, Klatka J. Preliminary results of prognostic significance of proliferating cell nuclear antigen expression in advanced primary larynx carcinomas and lymph node metastases. Arch Med Sci 2010; 6: 65-70

8. Kaczka K, Fendler W, Borowiec M, et al. One-step nucleic acid amplification testing in medullary thyroid cancer lymph nodes: a case series. Arch Med Sci 2015; 11: 137-41.

9. Notomi T, Okayama H, Masubuchi H, et al. Loop-mediated isothermal amplification of DNA. Nucleic Acids Res 2000; 28: E63.

10. Tsujimoto M, Nakabayashi K, Yoshidome K, et al. Onestep nucleic acid amplification for intraoperative detection of lymph node metastasis in breast cancer patients. Clin Cancer Res 2007; 13: 4807-16.

11. Guillén-Paredes MP, Carrasco-González L, Cháves-Benito A, Campillo-Soto A, Carrillo A, Aguayo-Albasini JL. One-step nucleic acid amplification (OSNA) assay for sentinel lymph node metastases as an alternative to conventional postoperative histology in breast cancer: a cost-benefit analysis. Cir Esp 2011; 89: 456-62.

12. Vogelaar FJ, Reimers MS, van der Linden RL, et al. The diagnostic value of one-step nucleic acid amplification (OSNA) for sentinel lymph nodes in colon cancer patients. Ann Surg Oncol 2014; 21: 3924-30.

13. Güller U, Zettl A, Worni M, et al. Molecular investigation of lymph nodes in colon cancer patients using one-step nucleic acid amplification (OSNA): a new road to better staging? Cancer 2012; 118: 6039-45.
14. Croner RS, Geppert Cl, Bader FG, et al. Molecular staging of lymph node-negative colon carcinomas by one-step nucleic acid amplification (OSNA) results in upstaging of a quarter of patients in a prospective, European, multicentre study. Br J Cancer 2014; 110: 2544-50.

15. Kumagai K, Yamamoto N, Miyashiro I, et al. Multicenter study evaluating the clinical performance of the OSNA assay for the molecular detection of lymph node metastases in gastric cancer patients. Gastric Cancer 2014; 17: 273-80.

16. Hayama M, Chida M, Karube $Y$, et al. One-step nucleic acid amplification for detection of lymph node metastasis in lung cancer. Ann Thorac Cardiovasc Surg 2014; 20: 181-4.

17. Inoue M, Hiyama K, Nakabayashi K, et al. An accurate and rapid detection of lymph node metastasis in nonsmall cell lung cancer patients based on one-step nucleic acid amplification assay. Lung Cancer 2012; 78: 212-8.

18. Matsuzuka T, Takahashi K, Kawakita D, et al. Intraoperative molecular assessment for lymph node metastasis in head and neck squamous cell carcinoma using onestep nucleic acid amplification (OSNA) assay. Ann Surg Oncol 2012; 19: 3865-70.

19. Goda H, Nakashiro K, Oka R, et al. One-step nucleic acid amplification for detecting lymph node metastasis of head and neck squamous cell carcinoma. Oral Oncol 2012; 48: 958-63

20. Nagai T, Niikura $H$, Okamoto $S$, et al. A new diagnostic method for rapid detection of lymph node metastases using a one-step nucleic acid amplification (OSNA) assay in endometrial cancer. Ann Surg Oncol 2015; 22: 980-6.

21. Okamoto S, Niikura H, Nakabayashi K, et al. Detection of sentinel lymph node metastases in cervical cancer: assessment of KRT19 mRNA in the one-step nucleic acid amplification (OSNA) method. Gynecol Oncol 2013; 130: 530-6.

22. Kaczka K, Fendler W, Borowiec M, Młynarski W, Pomorski L. First one-step nucleic acid amplification testing in papillary thyroid cancer lymph nodes - a comparison with histopathology and real-time PCR. Endokrynol Pol 2014; 65: 422-30.

23. González O, Iglesias C, Zafon C, et al. Detection of thyroid papillary carcinoma lymph node metastases using one step nucleic acid amplification (OSNA): preliminary results. J Invest Surg 2015; 28: 153-9.

24. Jarząb B, Sporny S, Lange D, et al. Diagnosis and treatment of thyroid cancer - Polish guidelines. Endokrynol Pol 2010; 61: 518-68.

25. Vassiliou I, Tympa A, Arkadopoulos N, Nikolakopoulos F, Petropoulou T, Smyrniotis V. Total thyroidectomy as the single surgical option for benign and malignant thyroid disease: a surgical challenge. Arch Med Sci 2013; 21: 74-8.

26. Kelemen PR, Van Herle AJ, Giuliano AE. Sentinel lymphadenectomy in thyroid malignant neoplasms. Arch Surg 1998; 133: 288-92.

27. Gallowitsch HJ, Mikosch P, Kresnik E, Starlinger M, Lind P. Lymphoscintigraphy and gamma probe-guided surgery in papillary thyroid carcinoma: the sentinel lymph node concept in thyroid carcinoma. Clin Nucl Med 1999; 24: 744-6.

28. Sahin M, Yapici O, Dervisoglu A, et al. Evaluation of lymphatic drainage of cold thyroid nodules with intratumoral injection of Tc-99m nanocolloid. Clin Nucl Med 2001; 26: 602-5. 
29. Balasubramanian SP, Brignall J, Lin HY, et al. Sentinel node biopsy in papillary thyroid cancer: what is the potential. Langenbecks Arch Surg 2014; 399: 245-51.

30. Raijmakers PG, Paul MA, Lips P. Sentinel node detection in patients with thyroid carcinoma: a meta-analysis. World J Surg 2008; 32: 1961-7.

31. Peparini N, Maturo A, Di Matteo FM, Tartaglia F, Marchesi M, Campana EP. Blue-dye sentinel node mapping in thyroid carcinoma: debatable results of feasibility. Acta Chir Belg 2006; 106: 523-7.

32. Kaczka K, Celnik A, Luks B, Jasion J, Pomorski L. Sentinel lymph node biopsy techniques in thyroid pathologies: a meta-analysis. Endokrynol Pol 2012; 63: 222-31.

33. Kaczka K, Luks B, Jasion J, Pomorski L. Sentinel lymph node in thyroid tumors - own experience. Contemp Oncol (Pozn) 2013; 17: 184-9.

34. Kliseska E, Makovac I. Skip metastases in papillary thyroid cancer. Coll Antropol 2012; 36 Suppl 2: 59-62.

35. Park JH, Lee YS, Kim BW, Chang HS, Park CS. Skip lateral neck node metastases in papillary thyroid carcinoma. World J Surg 2012; 36: 743-7.

36. Lim YC, Koo BS. Predictive factors of skip metastases to lateral neck compartment leaping central neck compartment in papillary thyroid carcinoma. Oral Oncol 2012; 48: 262-5.

37. Chow TL, Lim BH, Kwok SP. Sentinel lymph node dissection in papillary thyroid carcinoma. ANZ J Surg 2004; 74: 10-2.

38. Takeyama H, Tabei I, Uchida K, Morikawa T. Sentinel node biopsy for follicular tumours of the thyroid gland. Br J Surg 2009; 96: 490-5.

39. Coget J, Pocard M. The intraoperative study of the sentinel lymph node was made possible through molecular analysis: a new concept and new applications for colon cancer? Bull Cancer 2014; 101: 364-7. 